\title{
Sorting out of Gusevogorsk deposit titaniferous magnetite ore by technological types by methods of geoinformation modeling and preliminary estimation of their washability
}

\author{
Sergey Kornilkov ${ }^{1}$, Valery Kantemirov ${ }^{1}$, Andrey Yakovlev $^{1 *}$ and Roman Titov ${ }^{1}$ \\ Institute of Mining, Ural Branch of the Russian Academy of Sciences, Ekaterinburg, Russia.।
}

\begin{abstract}
A more complete and complex extraction of valuable components in the development of mineral resources is achieved through the separation of technological types and grades of ores, their separate extraction and processing, which allows to increase the yield, quality and nomenclature of commercial products and to raise the economic efficiency of the extraction and preparation processes. An important element of the separate processing of types of ores is the technology used for their zoning by grades in the open-pit space. Innovative direction in the development of the forecast of quality and preparation characteristics of mineral resources is the methods of geoinformation modeling with the use of Geological and Mining Information System technologies. The paper describes the technique of modeling and separation of ores into technological grades on the example of the Gusevogorskoye deposit of titanomagnetites, and presents the method of express ore preparability analysis with the estimation of the degree of contrast of qualitative characteristics.
\end{abstract}

\section{Introduction}

The most iron ore mining and processing stations (MPS) have adopted gross mining, averaging and ore preparation according to a single technological scheme, which simplifies the organization of extraction and preparation of mineral resources. One of the possible ways to improve the quality of iron concentrate is the separate extraction and processing at the concentrator of various natural types of ores. As a characteristic object for the implementation of these measures, it is possible to consider the deposits of titanomagnetites of the Kachkanar group, for which a number of researchers [1,2] substantiated the technological possibilities for producing the iron-vanadium and separately ilmenite concentrate and the expediency of additional ore separation into natural grades depending on the content of titanium dioxide.

The Kachkanar titanomagnetite massif is located in the north of the Sverdlovsk region and is represented by two deposits: Gusevogorskoye and Sobstvenno-Kachkanarskoe. The

\footnotetext{
*Corresponding author:quality@igduran.ru
} 
host rocks are represented by plagioclase porphyrites, effusive diabases, mica and siliceous shales of the Ordovician. Mineralization is confined to pyroxenites, and the structures and textures of ores correspond to the structures and textures of the host rocks. The shape of the ore bodies is the shallow and inclined long deposits of disseminated and banded titanomagnetite ores. The ore at the Gusevogorskoye deposit is extracted by three open-pit mines: Main, Northern and Western.

It is assumed that the titaniferous magnetite ore of the Gusevogorskoye deposit is represented by two major natural types (species) of ore - low-Ti type (the contents of $\mathrm{TiO}_{2}$ $<1.1 \%$ ) and normal-Ti type (content of $\mathrm{TiO}_{2} \geq 1,1 \%$ ). The main quantity of low-Ti ores is extracted in the Western open-pit mine. The low-Ti grade has higher preparability. At the same time, the smaller the size of grains of titanomagnetite, the greater the difference in iron content in concentrates obtained from low-Ti and normal-Ti ore. On the example of the Gusevogorskoye deposit, a method for geometrization has been developed and tested that allows:

- to carry out the forecast of distribution of qualitative indicators in mineral resources;

- to separate ores into technological grades;

- to assess the possibility of separate extraction and processing;

\section{Methods of experimental work}

Analysis of literature sources [3] and geological reports has allowed to systematize the current criteria for the separation of technological types of ores of the Gusevogorskoye deposit, depending on the following factors:

1) impregnation of grains of titanomagnetite in ore:

- easy-preparable - large- (>3 mm) and medium-impregnated (1-3 mm);

- medium-preparable - small-impregnated $(0.2-1 \mathrm{~mm})$;

- hard-preparable - thin- $(0,074-0,2 \mathrm{~mm})$ and disperse-impregated $(<0,074 \mathrm{~mm})$;

2 ) the content of iron in the concentrate, \% - an empirical indicator that allows you to predict the preparability of mined ore in industrial plants:

- easy-preparable - the index of preparability being more than $64.4 \%$;

- normal-preparable - the index of preparability being from $62.6 \%$ to $64.4 \%$;

- hard-preparable - the index of preparability being from $60,1 \%$ to $62.6 \%$;

- very hard-preparable - the index of preparability being less than $60 \%$.

On the basis of statistical analysis and generalization of operating technological criteria to iron ore, a complex index of preparability has been established, taking into account the mutual influence of the iron content in the concentrate and the impregnated grains of titanomagnetite. The indicated characteristics of ores are used in the current planning of mining operations at the enterprise and are linked to the schedule of ore supply for processing. The evaluation of the ratio of technological grades of ore is carried out in order to adjust the productivity and operating conditions of the equipment in the processing sections of the preparation plant.

Geometrization of the index of preparability has been carried out according to the detailed exploration data of the Gusevogorskoye deposit, and the geological plans, sections, interval borehole columns with data on the content of iron, titanium, vanadium, the impregnations of titanomagnetite and iron content in the concentrate have been used as initial information. The entire array of information was collected in a single geological database, on the basis of which the peg mining models and block deposit models for three open-pit mines have been built: Main, Northern and Western. Also, the correlationregression analysis has been also performed, which allowed to establish zones with increased and lowered contents of chemical elements, based on the boundary value of iron 
and the features of the occurrence of ore bodies. The method of geometrization consists in the following sequence of operations:

- data conversion (digitization, data processing, building of numerical distributions characterizing spatial data placement and clustering, compositing);

- building of isosurfaces of qualitative indicators of working horizons by methods of triangulation and return distance with allocation of zones of increased / lowered content of mineral components (Fig. 1);

- building of block models and filling them with interpolated values of qualitative indicators by kriging;

- zoning of low-Ti and normal-Ti ores with the determination of the possibility of their separate extraction and preparation (Fig. 2).

- building of horizon-oriented plans reflecting the size and distribution of the impregnation and complex index of preparability (Fig. 2) of titanomagnetite ores in the working horizons of open-pit mines.

For comparison with the results of block modeling, the developed method for express estimation of the contrast of ores as a technological index characterizing the preparability (using the example of the horizon of $+160 \mathrm{~m}$ of the Northern open-pit mine) has been used.

The ore contrast is the degree of uneven distribution of the mineral component in the ore determined by its specified volumes. The larger this volume, the less contrast. The greatest contrast is observed in pieces of ore comparable with the volume of ore inclusions, and the smallest contrast being observed in large portions of crushed and mixed ore. [4]

To build a model, the borehole array under investigation is conditionally divided into equal sections-squares (with coordinates along the $\mathrm{X}, \mathrm{Y}$ axes). A total of 20 arbitrary squares have been selected (see Table 2, Fig. 2) with a step of $\amalg_{x}$ and $\amalg_{y}$ :

$$
\begin{aligned}
& \amalg_{x}=\frac{X_{\max }-X_{\min }}{5}, \\
& \amalg_{y}=\frac{Y_{\max }-Y_{\min }}{5},
\end{aligned}
$$

Where $\mathrm{X}_{\max }, \mathrm{X}_{\min }$ are the extreme marks of the coordinates of the boreholes along the $\mathrm{X}$ axis; $Y_{\max }, Y_{\min }$ are the extreme marks of the coordinates of the boreholes along the $Y$ axis;

A conditional square is assigned a number in accordance with the accepted coordinate system (for example, A3). The following characteristics are calculated in each square: the average content of valuable components in the ore - total iron, titanium and vanadium; coefficients of variation in content; contrast coefficients of content of valuable components. The results of calculations and modeling are presented in Table 2.

\section{Results and discussion}

Analytical evaluation of the results of the distribution modeling within the Northern openpit mine (horizon being $160 \mathrm{~m}$ ) of the impregnation and iron content in the magnetic fraction led to the conclusion that the ores of the north-eastern part of the deposit are more highly prepared.

To assess the possibility of separate mining, the horizon $160 \mathrm{~m}$ of the Northern mine has been divided into 18 peg models, each with an ore volume equal to the annual productivity of the medium-duty excavator, the estimation has been performed for the chemical composition and the index of preparability within each model, as well as the statistical characteristics of the distribution of valuable components. On the basis of the analysis it has been found that the individual peg models have a large percentage of offgrade ore in terms of total iron content, while at the same time a part of this ore is characterized by a complex index of preparability as normal-preparable, which makes it 
possible to use this ore with the organization of in-pit averaging with the aim of increasing the yield of commercial products.
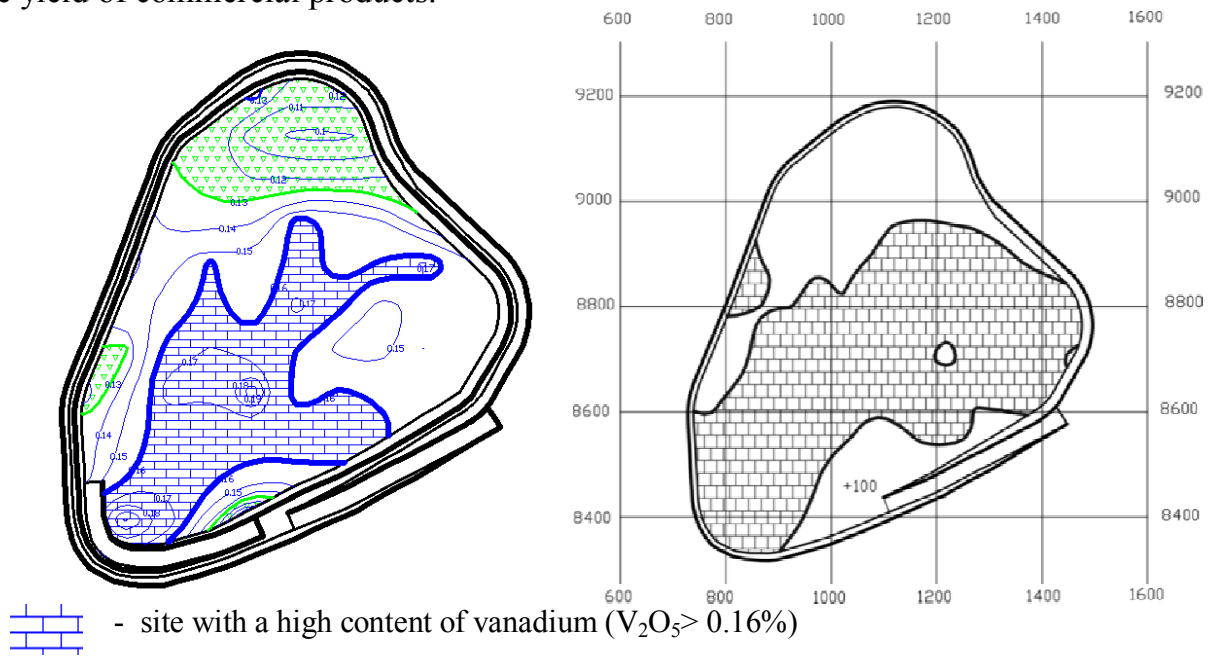

- site with a high content of vanadium $\left(\mathrm{V}_{2} \mathrm{O}_{5}>0.16 \%\right)$

- site with a reduced content of vanadium $\left(\mathrm{V}_{2} \mathrm{O}_{5}<0.13 \%\right)$

$\frac{1}{\stackrel{I}{I}}$ - section of normal-Ti ore $\left(\mathrm{TiO}_{2}>1.1 \%\right)$

Fig. 1. Distribution of vanadium and titanium content at the horizon of $+100 \mathrm{~m}$ of the Western mine of JSC "EVRAZ KGOK"

A comparative analysis of the distribution in open-pit mines of different technological types of ores according to the above presented estimation methods gives quite similar zoning results. It is established that the northern and western sections of the side are the main concentration of hard-preparable ores at the Northern mine, while these ores belonging to the class of not-contrast ores. The increase in titanium content in the ores of the Northern open-pit mine is oriented to the northeast, and within the Main open-pit mine to the southwest, for the Western open-pit mine from the west to the east. This trend can be traced for all working horizons of open-pit mines (for Northern open-pit mine see Table 1).

Normal-Ti ores have been localized in the Northern open-pit mine in its northeastern part and have been distributed everywhere in the Main open-pit mine except for the northwestern section. At the Western open-pit mine, low-Ti ores are located along the northern and southern sides.

Table 1. The ratio of normal-Ti and low-Ti ores at the working horizons of the Northern open-pit mine

\begin{tabular}{|c|c|c|}
\hline Horizon & Normal-Ti, $\%$ & Low-Ti, $\%$ \\
\hline$+205 \mathrm{~m}$ & 29.8 & 70.2 \\
\hline$+190 \mathrm{~m}$ & 28.2 & 71.8 \\
\hline$+175 \mathrm{~m}$ & 22.6 & 77.4 \\
\hline$+160 \mathrm{~m}$ & 39 & 61 \\
\hline Total: & 25.6 & 74.4 \\
\hline
\end{tabular}

Within the Northern open-pit mine, easy- and normal-preparable ores, as well as ultraand high-contrast ores selected by other methods, are located in the central part of the openpit mine, respectively. The total volumes of low-, normal- and medium-preparable ores established at the horizon $+160\left(14.6\right.$ million $\left.\mathrm{m}^{3}\right)$ correspond approximately to the volumes 
of ultra-contrast, high-contrast and contrast ores $\left(10.8\right.$ million $\left.\mathrm{m}^{3}\right)$ selected by the method of assessing the contrast, the difference being $\sim 30 \%$. It has been established that practically throughout the studied field, the contrast indices of titanium and vanadium in the ore are higher than in iron. It is assumed that the accuracy of the forecast can be increased by changing the size of the unit cells in the model and increasing their number in the express method for estimating the contrast of ores.

The results of the comparative analysis and the methods of estimating the qualitative characteristics of mineral resources with modeling the placement of technological types of ores in the open-pit space confirm the efficiency of their use in the preliminary stage of studying the geological information. It is established that the contrast between the elements within the horizon $+160 \mathrm{~m}$ of the Northern open-pit mine differs quite strongly, so on the western side of the open-pit mine there is a higher contrast of iron content than titanium (by 4 times). Table 2 shows the distribution of ore in terms of contrast within the horizon ${ }^{`}+160$ $m$ in the Northern open-pit mine.

Table 2. Distribution of ore by contrast ratio at the horizon $+160 \mathrm{~m}$

\begin{tabular}{|c|c|c|c|}
\hline \multirow{2}{*}{ Ore type by contrast } & \multicolumn{3}{|c|}{ Distribution over the horizon } \\
\hline & $\%$ & ths. $\mathrm{m}^{2}$ & ths. $\mathrm{m}^{3}$ \\
\hline Ultra contrast $(M>1.5)$ & 13.6 & 184.1 & 2762.2 \\
\hline High-contrast $(1.2<\mathrm{M}<1.5)$ & 24.7 & 334.4 & 5015.3 \\
\hline Contrast $(0.4<\mathrm{M}<1.2)$ & 33.8 & 457.1 & 6855.4 \\
\hline Not-contrast $(\mathrm{M}<0,4)$ & 26.8 & 363.1 & 5446.2 \\
\hline Missing data & 1.1 & 15.1 & 226.9 \\
\hline Total: & 100 & 1351 & 20266 \\
\hline
\end{tabular}

It is expected that developing the northern side and the central section makes it possible to minimize fluctuations in the quality characteristics of valuable components. It should be noted that the contrast ratio, characterizing a certain degree of heterogeneity of ore, does not fully reflect the technological results of ore preparation. Its use is recommended for preliminary qualitative analysis of complex ores with various mining methods, various schemes of ore preparation and roughing. 
a) 1
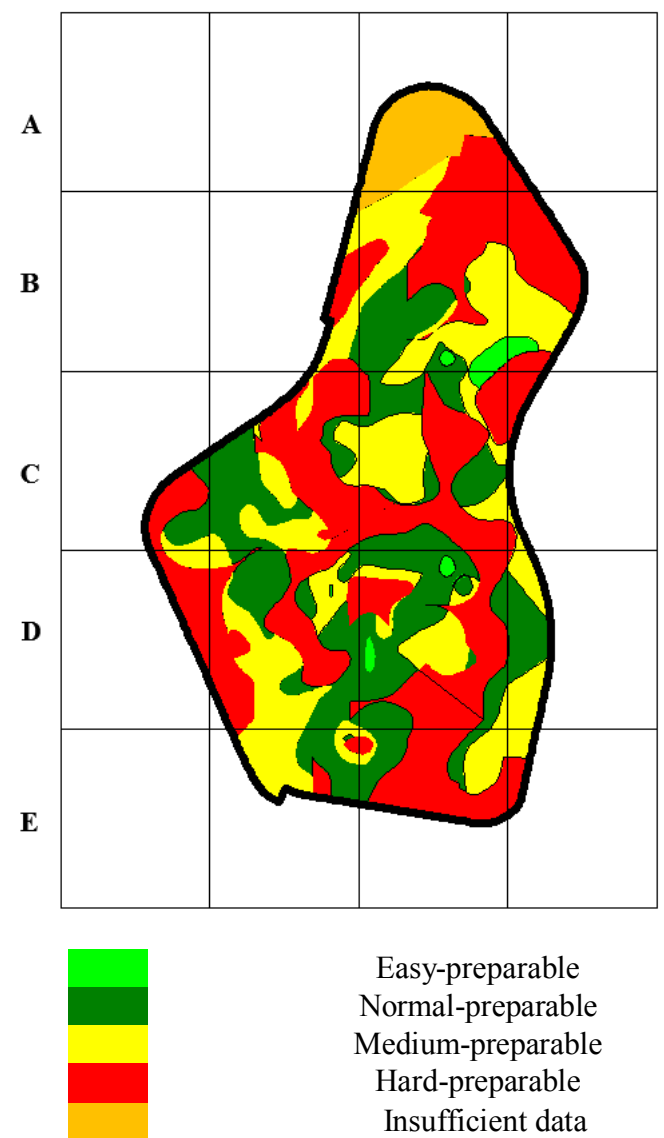

Easy-preparable

Normal-preparable

Medium-preparable

Hard-preparable

Insufficient data b)

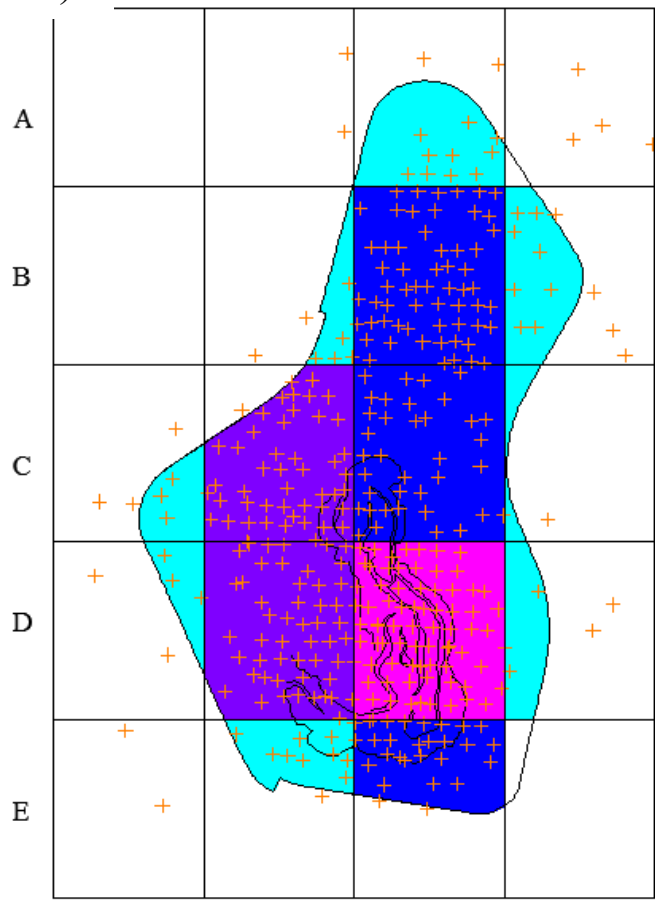

Ultra-contrast ores $(\mathrm{M}>1.5)$

High-contrast ores $(1.2<\mathrm{M}<1.5)$

Contrast ores $(0.4<\mathrm{M}<1.2)$

Not-contrast ores $(\mathrm{M}<0.4)$

Fig. 3. Zoning of titanomagnetite ores at the Northern open-pit mine of JSC "EVRAZ KGOK": a) on the complex index of preparability (the content of iron in the magnetic fraction and the size of the impregnation); b) on the contrast ratio

\section{Conclusions}

With a comprehensive assessment of mineral resources, modern standards presume to take into account not only the content of mineral components and deleterious impurities, but also structural and texture features of ores, as well as the requirements of concentrating and metallurgical processing in order to achieve the maximum yield of a quality commercial product.

An estimation of the contrast of chemical and textural-structural properties of mineral resources can be used to justify the choice of technological ore-preparation schemes in the open-pit mine (averaging, grading, selective development, preenriching, etc.). The main advantages of this assessing method are the speed of obtaining the esimation results without using expensive software products. Improving the method requires its further development to improve the accuracy of the forecast and to approach the results of "classical" block modeling using laborious methods of geostatistics.

The studies carried out by IM UrB RAS, IMET UrB RAS, in cooperation with the Mineral Processing Department of the Ural State Mining University, have revealed significant differences in the preparability and grindability of the low-Ti and normal-Ti 
grades of ore and recommended their separation into various technological types with subsequent processing on separate processing lines. At the same time, the total technological and economic indices of separate preparation of natural types of ores will be higher than those of ore preparation in industrial-scale mining. The results of the research have showed that the low-Ti grade of ore as compared to the normal-Ti ore has higher preparability and grindability and less magnetic rigidity. Therefore, it is recommended to introduce an additional parameter for geometrization, such as the limiting content of titanium dioxide in mined ore, into the current classification of ore preparation, in addition to the indicators taken at the MPS (the grain size of titanomagnetite and the total iron content in the concentrate).

The preliminary analysis has shown that the Gusevogorskoye deposit's concentrates obtained as a result of separate extraction and preparation should be reasonably processed in the near future according to the "blast furnace - converter" scheme. When replacing the ores of the Western open-pit mine with the mineral resources of the SobstvennoKachkanarskoye deposit, the Northern open-pit mine becomes the object that systematically ensures the formation of ore flows of a given quality.

The obtained results allow us to carry out the preliminary horizon-oriented estimation in open-pit mine the degree of variability of mineral components in ore and make a forecast for the distribution of certain types of ores in order to distinguish further the technological types of ores for mining planning tasks and to control the quality of mineral resources and improve the efficiency of ore preparation.

\section{References:}

1. D. E. Mansor, "Development of Technologies for Complex Processing of Vanadium Containing Titanomagnetites" / D. E. Mansor and B. S. Tleugabulov // Juvenis scientia. 1, pp. 13-15. (2016) [In Russian].

2. N. Dmitriev, G. Yu. Vitkina, R. V. Petukhov, S. V. Kornilkov, A. E. Pelevin, A. Y. Fishman, T. V. Sapozhnikova and K. Y. Shunyaev, "The Characteristic of Ores and Concentrates of the Open Society EVRAZ KGOK", Advanced Materials Research. 834 836. Pp. 364 - 369. (2014).

3. M. V. Vasiliev, V. L. Yakovlev et al. Transport of Open-Pit Mines, (SredneUralskoe Knizhnoe Izdatelstvo, Sverdlovsk) [In Russian].

4. L. Ch. Pukhalsky, The Theory of the Contrast of Uranium Ores, (Gosatomizdat, Moscow, 1963) [In Russian]. 